\title{
Fish Behaviour and Immune Response as a Potential Indicator of Stress Caused by 4-Nonylphenol
}

\author{
Madhu Sharma ${ }^{1}$, Pooja Chadha ${ }^{1,}$, Manoj Kumar Borah ${ }^{2}$ \\ ${ }^{1}$ Department of Zoology, Guru Nanak Dev University, Amritsar, Punjab, India \\ ${ }^{2}$ Department of Veterinary Pathology, Khalsa College of Veterinary and Animal Sciences, Amritsar, Punjab, India
}

Email address:

poojachadha77@yahoo.co.in (P.Chadha)

To cite this article:

Madhu Sharma, Pooja Chadha, Manoj Kumar Borah. Fish Behaviour and Immune Response as a Potential Indicator of Stress Caused by 4Nonylphenol. American Journal of BioScience. Vol. 3, No. 6, 2015, pp. 278-283. doi: 10.11648/j.ajbio.20150306.21

\begin{abstract}
The present investigation was undertaken to study the stress response in fish Channa punctatus after treatment with 4-nonylphenol. Stress response was measured by studying the change in behaviour and immume system. After range finding experiment fish were exposed to 5 concentrations of 4-NP and $\mathrm{LC}_{50}$ was determined $\left(\mathrm{LC} 50_{5}=1.27 \mathrm{mg} / \mathrm{l}\right)$. Simultaneously behavioural response was observed for 96 hours of exposure. After $\mathrm{LC}_{50}$ determination three sublethal concentrations were decided and fish were exposed for 24, 48, 72 and 96 hours and differential leucocytes count was calculated. Significant change in the number of lymphocytes, monocytes and neutrophils was seen. This study concludes that fish immune system and behaviour are most sensitive parameters to study the stress level in fish.
\end{abstract}

Keywords: Behaviour, Leucocytes, Lymphocyte, Monocytes, Neutrophils

\section{Introduction}

NPEs are highly cost effective surfactants and hence widely used in industrial and household applications. Their use is growing day by day in developing countries like China and India. According to a study conducted by [1] level of NP in Indian river was exceeding the drinking water permissible limit. Microbial transformation usually reduces the environmental toxicity of a compound; but in some cases, breakdown products are much more toxic than the parent compounds [2]. Therefore, to gauge the environmental toxicity of such compounds toxicity testing might be done on final degradation products. Ubiquitous, persistent and easily bioaccumulative nature of NP and NPEs has attracted researcher's attention from the past couple of years [3].

Differential leucocyte counts and behaviour belong to important biomarkers of the fish health status. Non specific response in fish can be evoked by physical, chemical and perceived stressors, which is important to maintain the homeostatic state and enable fish to cope with disturbances. But if stress last for longer duration, it can threaten the well being of fish [4]. Change in behavior can be noticed when the animal is exposed to a chemical concentration below than that can cause mortality [5]. The multidisciplinary research is required to increase the usefulness and significance of behavioral indicators [6].

Behavioral changes shown by any organism in response to any chemical, depend upon their mode of action [7]. Behavioral changes in response to certain chemicals like chlorpyriphos [8], chromium [9], polychlorinated biphenyls and tributyltin [10] have been investigated.

There is an association between circulatory system and external environment and study of different types of blood cells were used to study the effect of external stressors and toxic chemicals [11]. Change in environmental conditions may leads to damage in heamapoietic organs in fish, which may lead to change in number and morphology of blood cells [12]. Different stressors in environment may lead to change in leucocytes profile and elicit a stress response [13].

The differential leukocyte count, like other hematological parameters, is dependent on the fish species, physiological age, sex, season of the year and different methods of rearing and nutrition [14]. Stress caused by several of pollution indicator can bring a marked change in the percentage and absolute numbers of individual types of leukocytes [15]. Severe or chronic stress is often associated with poor performance and has long been associated with immunosuppression in fish. 
Lymphocytes, monocytes and neutrophils numbers are known to change according to the physiological condition of the fish. Decreased lymphocyte numbers were observed under stressed conditions - hypoxia, cortisol induced or during handling and transport [12].

C. punctatus is an excellent test specimen for toxicity studies due to its wide distribution in the freshwater environment, availability throughout the year, easy acclimatization to laboratory conditions and its commercial importance [16].

\section{Materials and Method}

\subsection{Experimental Fish Specimen and Chemical}

Fresh water air breathing fish C. punctatus were procured from local fish market having weight $17 \pm 2 \mathrm{~g}$ and measured $12 \pm 2 \mathrm{~cm}$. Fish was treated with $0.02 \% \mathrm{KMnO}_{4}$ for 2 minutes to avoid any dermal infection. The fishes were then acclimatized for 15 days under laboratory in static conditions and kept in rectangular glass aquaria of capacity 200 litres. They were fed with boiled egg. The faecal matter and other waste material were siphoned off daily to reduce ammonia content in water. 4-Nonylphenol used as test chemical obtained from himedia (India).

\section{2. $L C_{50}$ Determination and Behavioural Study}

Preliminary tests were performed to determine appropriate range of toxicity of NP. A set of 10 specimens were randomly exposed to each of the five concentrations $(0.8$, $1.1,1.4,1.7,2 \mathrm{mg} / 1)$. Behavioural studies were done during $96 \mathrm{hrs}$ exposure to these five concentrations. The physicochemical properties of test water, namely temperature, $\mathrm{pH}$, DO, TDS, Alkalinity, Free $\mathrm{CO}_{2}$, TSS were analyzed by standard methods [17] given in table- 1 . The $95 \%$ confidence limit value was calculated using Probit method as described by [18]. $\mathrm{LC}_{50}$ for NP comes out to be $1.27 \mathrm{mg} / \mathrm{l}$. Based on $\mathrm{LC}_{50}$ value three sub lethal concentrations 0.158 (1/8), $0.317(1 / 4), 0.635(1 / 2)$ of $\mathrm{LC}_{50}$ were chosen and fishes were exposed to these sub lethal concentrations for $24,48,72$ and 96 hours to see the effect on haematological profile.

\subsection{Differential Leukocyte Count}

For differential leukocyte count blood smear is made immediately after taking blood. Dried at room temperature and then fixed in ethanol for 10 minutes. Differential WBCs were counted in blood smear after staining the slides with Wright stain for 30 minutes, dried and observed under microscope. 100 WBC's were counted with blood cell counter.

\subsection{Statistical Analysis}

The results are expressed as mean \pm S.E. The Tukey-HSD test was considered for multiple comparisons and designed to study significance of difference in the different leukocytes among treated and control groups at different time intervals. One way analysis of variance was applied to assess the effect of concentration and time duration.

Table 1. Showing range of different water parameters.

\begin{tabular}{l|l}
\hline Parameter & Range \\
\hline Temperature & $15.2-19.80 \mathrm{C}$ \\
$\mathrm{pH}$ & $7.55-8.29$ \\
$\mathrm{DO}$ & $2.8-4.8 \mathrm{mg} / 1$ \\
Conductivity & $0.575-0.858 \mathrm{~ms} / \mathrm{cm}$ \\
TDS & $0.289-0.470 \mathrm{gm} / 1$ \\
Salinity & $0-0.24 \mathrm{mg} / 1$ \\
\hline
\end{tabular}

Table 2. Impact of 4-NP on behavior of a teleost fish, Channa punctatus for 96 hours.

\begin{tabular}{|c|c|c|c|c|c|c|}
\hline Parameters & Control & Conc. 1 & Conc. 2 & Conc. 3 & Conc. 4 & Conc. 5 \\
\hline Hyperactivity & - & + & ++ & ++ & +++ & +++ \\
\hline $\begin{array}{l}\text { Loss of } \\
\text { balance }\end{array}$ & - & + & ++ & ++ & +++ & +++ \\
\hline $\begin{array}{l}\text { Rate of } \\
\text { Swimming }\end{array}$ & + & + & + & ++ & ++ & +++ \\
\hline $\begin{array}{l}\text { Rate of } \\
\text { Operculum } \\
\text { activity }\end{array}$ & + & ++ & ++ & ++ & +++ & +++ \\
\hline Pigmentation & - & ++ & ++ & +++ & +++ & +++ \\
\hline
\end{tabular}

$(-)$ None, $(+)$ mild, $(++)$ Moderate, $(+++)$ Strong

Table 3. Determination of $L C_{50}$ value of $4-N P$ in C. punctatus for 96 hours.

\begin{tabular}{lllll}
\hline Chemical & Fish & Upper limit & Lower limit & LC $_{\mathbf{5 0}}$ \\
\hline 4-NP & C.punctatus & 1.33 & 1.21 & $1.27 \mathrm{mg} / 1$ \\
\hline
\end{tabular}

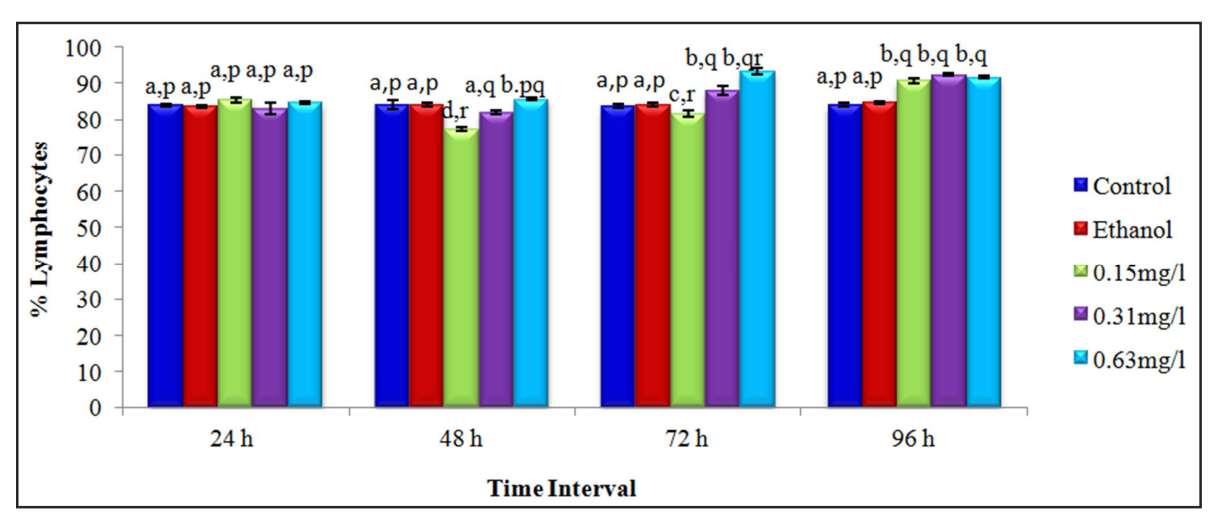

Figure 1. Percent lymphocytes in blood of C. punctatus after treatment with different concentrations of 4-nonyphenol at different time intervals. 


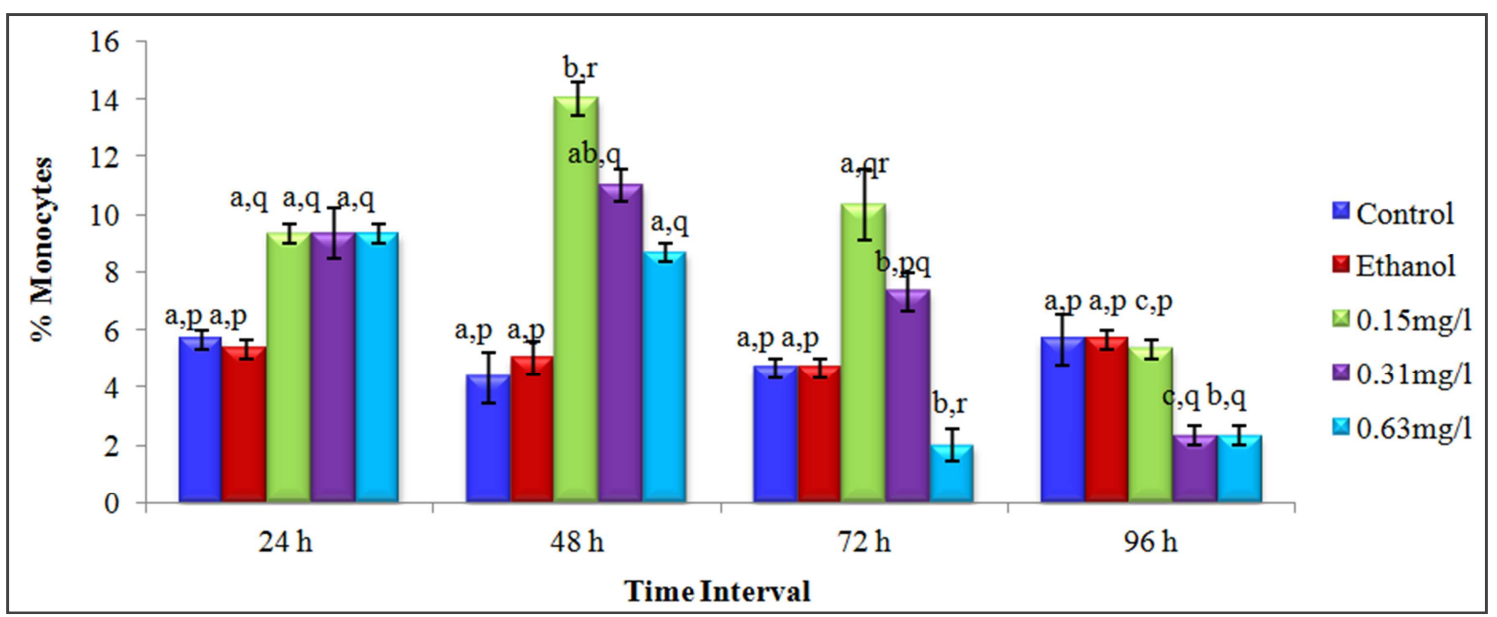

Figure 2. Percent monocytes in blood of C. punctatus after treatment with different concentrations of 4-nonylphenol at different time intervals.

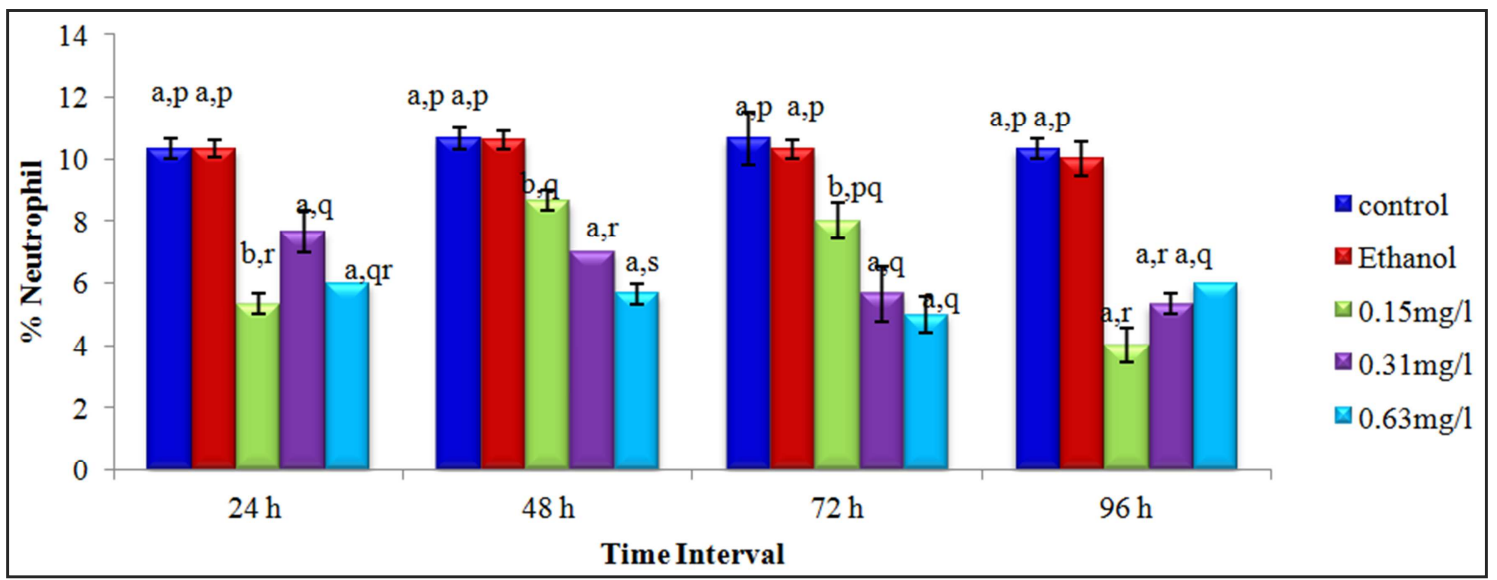

Figure 3. Percent Neutrophils in blood of C. punctatus after treatment with different concentrations of 4-nonylphenol at different time intervals.

Values given as mean \pm standard error. Different letters (a, $b, c, d$ ) are significantly different (Tukey's test, $p \leq 0.01$ ) and signify the effect of duration of exposure at each concentration. Similarly, different letters ( $\mathrm{p}, \mathrm{q}, \mathrm{r}, \mathrm{s})$ are significantly different (Tukey's test, $p \leq 0.01$ ) and signify the effect of different concentrations of 4-nonylphenol at the same time interval.

\section{Results}

\subsection{Fish Behaviour and Mortality}

As soon as the fish were added to water containing 4nonylphenol change in behavior was observed. Table-2 reveals the different behavioral changes observed in Channa punctatus after treatment with different concentrations of 4NP for 96 hours. Change in behavior was even observed in lowest concentration. Abnormal behavior observed in the study include erratic movement, accelerated respiration, high operculum movement, loss of equilibrium, reduced reflexes, high pigmentation and high mucous secretion. Fish were found at the corner of the tank and curving of spin was also found. At the end, fish loss complete reflexes and mouth came to surface for gulping air. Finally fish died and get settled at the bottom of the tank. No behavioral changes were observed in control fish. Highest death was found in the tank with highest concentration. Fish mortality was found even after 24 hours of exposure and a dose and time dependent increase in mortality was found. Highest mortality was found at highest concentration after 96 hours of exposure. $\mathrm{LC}_{50}$ value for 4-NP in fish C. punctatus was found to be $1.27 \mathrm{mg} / \mathrm{l}$ for 96 hours of exposure (Table-3).

\subsection{Differential Leukocyte Count}

Differential count of white blood cells showed changes after exposure of fish to sub lethal concentrations of 4nonylphenol as compared to control fish. Lymphocytes (\%) increased significantly at $(\mathrm{p} \leq 0.05)$ after exposure, while neutophils (\%) and monocytes (\%) decreased significantly at $(\mathrm{p} \leq 0.05)$ after exposure to 4-nonylphenol as compared with control. In a control group number of lymphocytes is $84 \%$ (Figure-1). But after treatment with 4-NP significant change in lymphocyte number was found. Highest effect was seen at 72 hours of exposure after treatment with $0.63 \mathrm{mg} / 1$ concentration. ANOVA shows that change at all the concentration and time duration was significant except at 24 hours $(p \leq 0.01)$. Tukey's test shows significant change between all the time intervals at $0.15 \mathrm{mg} / 1$ concentration, while at $0.31 \mathrm{mg} / 1$ and $0.63 \mathrm{mg} / 1$ concentration significant 
change was between 48 and 72 hours. Tukey's test reveals the significant changes between $0.15 \mathrm{mg} / 1$ and $0.31 \mathrm{mg} / 1$ concentrations at 48 and 72 hours.

Lowest value of monocytes was seen at $0.63 \mathrm{mg} / \mathrm{l}$ after 72 hours of exposure (Figure-2). ANOVA reveals that all the changes at each concentration and time interval were found to be significant. Tukey's test further reveals significant changes between all the time intervals for $0.15 \mathrm{mg} / \mathrm{l}$ and 0.31 $\mathrm{mg} / \mathrm{l}$ treatment groups, while at $0.63 \mathrm{mg} / \mathrm{l}$ concentration significant change is seen between 48 and 72 hours of exposure. Further tukey's test shows that at 48 and 96 hours significant change is seen between $0.15 \mathrm{mg} / \mathrm{l}$ and $0.63 \mathrm{mg} / \mathrm{l}$ concentration, further at 72 hours significant change is observed between all the hours of exposure.

Significant change in the value of neutrophils observed at only $0.15 \mathrm{mg} / 1$ concentration $(\mathrm{p} \leq 0.01)$. Further tukey's test shows that at $0.15 \mathrm{mg} / \mathrm{l}$ concentration, significant change is between 72 and 96 hours of exposure (Figure-3). ANOVA reveals that change is significant at all the hours of exposure $(\mathrm{p} \leq 0.01)$. Further tukey's test shows that at 48 hours significant changes are observed between all the concentrations and at 96 hours it is between $0.31 \mathrm{mg} / \mathrm{l}$ and $0.63 \mathrm{mg} / \mathrm{l}$ concentrations.

\section{Discussion}

Major source of NP in aquatic system are domestic and industrial waste water and urban and agricultural runoff. Once released into the environment, these compounds will climb the food chain up to humans in multiplying concentrations because of their bioaccumulation ability. Due to their physico-chemical properties such as lipophilicity and hydrophobicity, they accumulate in cells, tissues and organic materials such as sludge [19]. NP was found to be toxic $\left(\mathrm{LC}_{50}\right)$ to fish at concentrations from $17-3000 \mu \mathrm{g} / 1$ [20]. The value of $\mathrm{LC}_{50}$ of 4-nonylphenol in the present study came to be $1.27 \mathrm{mg} / \mathrm{l}$, indicating its high toxicity even at very low concentration.

Behavior is both a sequence of actions, operating through the central and peripheral nervous systems and the cumulative manifestation of genetic, biochemical and physiological processes essential to life, such as feeding, reproduction and predator avoidance [21]. Fish are able to uptake and retain different xenobiotics dissolved in water via active or passive processes. Any change in the behavior of fish indicates the deterioration of water quality. The performance of the normal behavior of individual fish follows specific physiological sequences which are triggered by external stimuli acting via a neural network [6]. Disruption of these sequences before completion is likely to result in detrimental behavioral alterations. Different chemicals can differ in the types of behaviors that they affect depending on their mode of action [22]. In the present investigation the control fish maintained in normal water were found to be active throughout the experiment, but the fish exposed to 4-nonylphenol showed abnormal behavior like erratic movement, increased operculum activity and reduced reflexes. High pigmentation as well as high mucus secretion was also observed. Avoidance behavior was shown by jerky moments and the fish often came to the surface for gulping air. Finally the fish settled at the bottom with loss of equilibrium and rolled its body prior to death. Different researchers have observed similar results in different fish species in response to various toxicants. Recently [23] found excessive mucus secretion, change in pigmentation, muscle fasciculation, refusal of feeding and respiratory distress in Catla catla in response to dimethoate. Similarly, gulping air, swimming at the water surface (surface phenomenon), loss of equilibrium, change in body colour, increase secretion of mucus and irregular swimming activity were observed by [24] in fish Clarias batrachus after exposure with copper sulphate. Faster opercular activity, jerky moments, erratic swimming and protrusion of eyes in gold fish after treatment with malathion and hinosan was reported by [25]. Neuotoxic effects like lateral side movement, loss of balance, movement in circular form with jerks and increased operculum activity in Labeo rohita exposed to chlorpyrifos were observed by [26].

The abnormal behaviors observed in the present study may be caused by the neurotoxic effects and also by the irritation to the perceptive system of the body. [27] have reported the deleterious effects of 4-NP on central nervous system as well as neuroendocrine homeostasis and cognitive functions. Inhibition of AChE activity due to the exposure of 4-NP activity in Mytilus galloprovincialis has been reported by [28]. So the abnormal behavior shown by fish may be due to abnormal level of neurotransmitters. Jumping to and fro signify the avoidance reaction of the fishes to the toxicants. Fish avoid the area containing chemical so mostly fishes were in the corners of the tank. Secretion of excessive mucus was probably due to irritation of the skin due to direct contact with the toxicant. Mucus forms a layer between the body and toxicant to minimize irritating effect and also inhibit the diffusion of oxygen during gaseous exchange [24]. Preference of upper layer may be due to elevated demand for oxygen due to respiratory stress in the exposed groups [29]. Lateral swimming and loss of equilibrium were probably due to the impairment of the nervous system [30]. Ultimately, fish sank into the tank bottom with a least operculum activity showing failure to fight with NP stress and ultimately the fish died. Inappropriate behavioral responses to environmental and physiological stimuli due to the toxic effect of aquatic contaminants can have severe implications for survival [31].

One of the most important pathophysiological reflectors of whole body organism is blood [32]. Alteration in immunological functions are regulated by leucocytes which may be connected to immune toxic potential of a substance. Change in leucocytes number indicate the response of fish organism to stress reaction [33].

The differential leucocyte count has been estimated in the study. The change in differential WBCs count can be used an indicator of stress reaction and for immunity decrease after exposure to toxic substances [33]. Despite some anatomical and physiological differences, the immune system of fish is similar to other vertebrates, and consists of various types of cells and chemical mediators. In fish, cellular and humoral, 
non-specific and specific immune mechanisms are present. Fish immune response may serve as an alternate or additional model for predicting the immunotoxicity of environmental contaminants as shown by many workers [34, 35].

The study shows that 4-nonylphenol caused immunological impairment in fish which weaken its immune system and may lead to severe physiological problems, ultimately leading to death of fish. The results also showed an increase in neutrophils and decrease in lymphocytes number and these results are in agreement with results of [13]. Differential leukocyte count showed a significant increase in the population of lymphocytes whereas neutrophils and monocytes were found to be decreased in $C$. punctatus after exposure to copper [36]. Similar increase in lymphocytes and decrease in neutrophils were found by [37] in fish $C$. punctatus after exposure to synthetic and plant origin pesticides. Decrease in monocyte number is observed by [38] in $C$. carpio in response to pyrethriod based pesticide. In contrast to this, [39] reported a significant decrease in lymphocytes, neutrophils and monocytes in $C$. carpio when exposed to cypermethrin. Decreased value of lymphocytes along with other haematological parameters was seen in L. rohita after exposure with butachlor [40]. When fish $C$. gariepinus were exposed with NPK fertilizer for 56 days, the number of neutrophils and monocytes get increased while lymphocyte number decreased [41].

From the present study it is concluded that 4-nonylphenol act as immunosuppressant and neurotoxic. Immune system and behavioral study are the sensitive parameters to study the stress level in fish.

\section{Acknowledgement}

The authors are sincerely thankful to DST-PURSE, UPE for funds and Head, Department of Zoology for providing laboratory facility.

\section{References}

[1] Selvaraj, K. K., Shanmugam, G., Sampath, S., Larsson, D. G. J. and Ramaswamy, B. R. GC-MS determination of bisphenol A and alkylphenol ethoxylates in river water from India and their ecotoxicological risk assessment. Ecotoxicol. Environ. Safety, 2014; 99: 13-20.

[2] Rizzo, L. Bioassays as a tool for evaluating advanced oxidation processes in water and wastewater treatment. Wat. Res, 2011; 45: 4311-4340.

[3] Lozano. N., Rice. C. P., Ramirez, M. and Torrents, A. (2012). Fate of Triclosan and Methyltriclosan in soil from biosolids application. Environ. Pollut, 2012; 160: 103-108.

[4] Barton, B. A. (2002). Stress in fishes: A diversity of responses with particular reference to changes in circulating corticosteroids. Integ. Com. Bio, 42: 517-525.

[5] Gerhardt, A. Aquatic behavioral ecotoxicology-prospects and limitations. Human Ecol. Risk Assessment, 2007; 13: 481491.
[6] Scott, G. R. and Sloman, K. A. The effects of environmental pollutants on complex fish behaviour: integrating behavioural and physiological indicators of toxicity. Aqua. Toxicol, 2004; 68: 369-392.

[7] Robinson, W. S. Ecological correlations and the behavior of individuals. International Journal of Epidemiology, 2009; 38: 337-341.

[8] Rice, P. J., Drewes, C. D., Klubertanz, T. M., Bradbury, S. P. and Coats, J. R. (1997). Acute toxicity and behavioral effects of chlorpyrifos, permethrin, phenol, strychnine, and 2,4dinitrophenol to 30-day-old Japanese medaka (Oryzias latipes). Environ. Toxicol. Chem. 1997; 16 (4): 696-704.

[9] Mishra, A. K. and Mohanty, B. (2008). Histopathological Effects of Hexavalent Chromium in the Ovary of a Fresh Water Fish, Channa punctatus (Bloch). Bull. Environ. Contam. Toxicol, 80 (6): 507-511.

[10] Schmidt, K., Steinberg, C. E. W., Pflugmacher, S. and Staaks, G. B. O. (2004). Xenobiotic substances such as PCB mixtures (Aroclor 1254) and TBT can influence swimming behavior and biotransformation activity (GST) of carp (Cyprinus carpio). Environ Toxicol, 2004; 19 (5): 460-470.

[11] Wendelaar Bonga, S. E. The stress response in fish. Physiol. Rev. 1997. 77: 591-625.

[12] Srivastva, S. and Choudhary, S. K. Effect of artificial photoperiod on the blood cells indices of the catfish Clarius batrachus. J. Stress Physiol. Biochem, 2010; 6(1): 22-32.

[13] Davis, A. K., Maney, D. L. and Maerz, J. C. The use of leukocyte profiles to measure stress in vertebrates: a review for ecologists. Functional Ecol, 2008; 22 (5): 760-772.

[14] Modra, H., Svobodova, Z. and Kolarova, J. Comparison of differential leucocyte count in fish of economic and indicator importance. Acta Veterinaria Brno, 1998; 67: 215-226.

[15] Ellis, E. A. and Roberts, R. J. Fish pathology. Bailliee Tindall, London. 1978; 318.

[16] Pandey, S., Kumar, R., Sharma, S., Nagpure, N. S., Srivastava, S. K., Verma, M. S. Acute toxicity bioassays of mercuric chloride and malathion on air breathing fish Channa punctatus (Bloch). Ecotoxicol. Environ. Saf, 2005; 61, 114 120.

[17] Xiao, H. Y., Shao, N. L., Zhang, L., Guo, N. Z. and Hui, S. Z. Evaluation of DNA damage in Chinese toad (Bufo bufo gargarizans) after in vivo exposure to sublethal concentrations of four herbicides using the comet assay. Ecotoxicol, 2008; 17: $280-286$.

[18] AWWA, APHA, WPCF (2005) Standard methods for the examination of water and wastewater, 21st ed edn. American Publication of Health Association, Washington, DC.

[19] McLeese, D. W., Zitko, V., Sergeant, D. B., Burridge, L and Metcalfe, C. D. Lethality and accumulation of alkylphenol in aqatic fauna. Chemosphere, 1981; 10: 723-730.

[20] Servos, M. R. Review of the aquatic toxicity, estrogenic response and bioaccumulation of alkylphenols polyethoxylates. Water Qual. Res. J. Canada, 1999; 34: 123177.

[21] Keenleyside, M. H. A. (1979) Diversity and adaptation in fish behaviour. Springer 208. 
[22] Robinson, W. S. (2009). Ecological correlations and the behavior of individuals. Inter. J. of Epidem, 2009; 38: 337341 .

[23] Hussain, M. I., Kumar, B. and Ahmad, M. (2015). Acute toxicity, behavioral response and biochemical composition of blood of common carp, Catla catla (Hamilton) to an organophosphate insecticide, Dimethoate. Inter. J. Curr. Micro. Applied Sci, 2015; 4(5): 1189-1199.

[24] Kumar, M., Kumar, P. and Devi, S. (2015). Toxicity of Copper Sulphate on Behavioural Parameter and Respiratory Surveillance in Freshwater catfish, Clarias batrachus (Lin.) Res. J. Chem. Environ. Sci, 2015; 3 (1): 22-28.

[25] Naserabad, S. S., Mirvaghefi, A., Gerami, M. H., Ghafari, H. and Farsani, 1. Acute toxicity and behavioral changes of the Gold Fish (Carassius auratus) exposed to malathion and hinosan. Iranian J. of Toxicol, 2015; 8 (27): 1203-1208.

[26] Ismail, M., Khan, Q. M., Ali, R., Ali, T. and Mobeen, A. (2014). Genotoxicity of chlorpyrifos in freshwater fish Labeo rohita using Alkaline Single-Cell Gel Electrophoresis (Comet) assay. Drug Chemi. Toxicol, 2014; 37 (4): 466-471.

[27] Jie, X., JianMei, L., Zheng, F., Lei, G., Biao, Z. and Jie, Y. (2013). Neurotoxic effects of nonylphenol: a review. Wien Klin Wochenschr, 2013; 125: 61-70.

[28] Vidal-Linan, L., Bellas, J., Fumega, J. and Beiras, R. Bioaccumulation of BDE-47 and effects on molecular biomarkers acetylcholinesterase, glutathione- $\mathrm{S}$-transferase and glutathione peroxidase in Mytilus galloprovincialis mussels. Ecotoxicol, 2015; 24: 292-300.

[29] Katja, S., Georg, B. O. S., Stephan, P. and Christian, E. W. S. Impact of PCB mixture (Aroclor 1254) and TBT and a mixture of both on swimming behavior, body growth and enzymatic biotransformation activities (GST) of young carp (Cyprinus carpio). Aqua. Toxicol, 2005; 71: 49-59.

[30] Sinha, T. K. P. and Kumar, K. Acute toxicity of mercuric chloride to Anabas testudineus (Bloch). Environ. Ecol, 1992; 10 (3): 720-722.

[31] Weber, D. N. and Spieler, R. E. Behavioral mechanisms of metal toxicity in fishes. In: Malins, D.C., Ostrander, G.K. (Eds.), Aquatic Toxicology: Molecular, Biochemical and Cellular Perspectives. CRC Press, London, UK. 1994, pp 421467.
[32] Adhikari, S., Sarkar, B., Chatterjee, A., Mahapatra, C. T. and Ayyappan, S. Effects of cypermethrin and carbofuran on certain hematological parameters and prediction of their recovery in a freshwater teleost, Labeo rohita (Hamilton). Ecotoxicol. Environ. Saf, 2004; 58 (2): 220-226.

[33] Ramesh, M., Srinivasan, R. and Saravanan, M. Effect of atrazine (Herbicide) on blood parameters of common carp, Cyprinus carpio (Actinopterygii: cypriniformes). African J. of Environ. Sci. Techno, 2009; 3 (12): 453 - 458.

[34] Tavares-Dias, M. and Moraes, F. R. Leukocyte and thrombocyte reference values for channel catfish (Ictalurus punctatus) with an assessment of morphological, cytochemical, and ultrastructural features. Vet. Clin. Pathol, 2007; 36: 49-54.

[35] Witeska, M., Knodera, E. and Lugowski, K. The effects of Ichthyophthiriasis on some hematological parameters in common carp. Turkish J. Vet. Ani. Sci, 2010; 34 (3): 267-271.

[36] Singh, N. K., Trivedi, S.P. and Sharma, Y. K. Impact of copper on haematological profile of freshwater fish, Channa punctatus. J. Environ. Biol, 2008; 29 (2): 253-257.

[37] Shahi, J., Chauhan, S. and Singh, A. Comparitive study on the haematological effect of synthetic and plant origin pesticides on the fish Channa punctatus. Ind. J. Nat. Pro. Res, 2013; 4 (1): 48-53.

[38] Venkatarama, M. G. V. and Sandhya Rani, P. N. Acute toxicity and blood profile of freshwater fish, Clarias batrachus (Linn.) exposed to malathion. J. Academia and Indust. Res, 2013; 2: 3.

[39] Queensly, C., Venkadesh, C. and Kumaran, T. Impact of cypermethrin on some haematological parameters in a fresh water fish, Cyprinus carpio L. Inter. J. Development Res, 2015; 5 (1): 2899-2903.

[40] Ghaffar, A., Hussain, R., Khan, A., Abbas, R. Z. and Asad, M. Butachlor induced clinicohematological and cellular changes in freshwater fish Labeo rohita (Rohu). Pak. Vet. J, 2015; 35 (2): 201-206.

[41] Ajima, M. N. O., Ogo, O. A., Akpa, L. E. and Ajaero, I. Biochemical and haematological responses in African catfish Clarias gariepinus following chronic exposure to NPK (15:15:15) fertilizer. African J. of Aqua. Sci, 2015; 40: 73-79. 